\title{
20 THE SLIGHT SURPRISE OF INTEGRATION
}

\author{
Gunnar Ellingsen \\ Department of Telemedicine \\ University of Tromosø \\ Tromsø, Norway \\ Eric Monteiro \\ Department of Computer and Information Science \\ Norwegian University of Science and Technology \\ Trondheim, Norway
}

\begin{abstract}
Western hospitals of some size are characterized by a proliferation of nonintegrated information systems, resulting in considerable frustration both among users and information technology personnel. Consequently there have been many integration efforts. Such efforts typically include some or all of the four principle classes of hospital-based systems: electronic patient records, laboratory systems, radiology systems and patient administrative systems. In this study, we trace the implementation process during most of 2004 at the University Hospital of North Norway, where these systems were part of a larger replacement project. We analyze the images and visions of order and perfection serving as a foundation for the decision to replace the existing IT portfolio. Furthermore, we analyze the manner and form in which unintended consequences of the integrated solutions appear and, finally, how the very act of integration may indeed produce rather than curb disorder. As a result, a lack of integration of any reasonably complex information system is an immanent feature.
\end{abstract}

Keywords Hospital information systems, EPR, integration, order perfection

\section{INTRODUCTION}

- Perfectionism would be dangerous. John Law 
The health care sector in general, and Western hospitals in particular, are characterized by a proliferation of information systems. More likely than not, a hospital of some size will harbor a seemingly unmanageable collection of different information systems, including specialized ones designed by entrepreneurial users for local needs. A symptomatic expression of this is the observation that many information technology departments in hospitals often do not know-but resort to crude estimates - which information systems are really in operation. In contrast with the promises of ubiquitous information environments, the availability of computational power and services at all times in all places (Buderi 2001), the acute challenges for users of information systems in hospitals are directly related to the lack of integration.

Hospitals are thus fertile breeding grounds for considerable frustration and dissatisfaction. For these reasons, hospitals provide a particularly fruitful site to explore efforts of integration of information systems, a challenge highly relevant to larger public and business organizations. Traditional approaches to integration in IS are dominated by technical solutions (Liu et al., 2001; Tsiknakis et al., 2002). Our perspective, strongly influenced by recent work (Berg 1998; Ellingsen and Monteiro 2003; Procter et al. 2003), recognizes the technical problem of integration as deeply embedded in organizational issues of collaboration and coordination.

Empirically, we trace the implementation process during most of 2004 at the University Hospital of North Norway (UNN), where an existing electronic patient record (EPR) system (by Siemens called DocuLive EPR) was replaced with another (called Dips). EPR systems form one out of four major classes of information systems in hospitals. The other three are laboratory systems, radiology systems (RIS/PACS), and patient administrative systems (PAS). The (lack of) integration between these four core applications was an influential element in the whole replacement process. Our analysis focuses on three aspects of integration.

First, the replacement of the old EPR took many by surprise. It was the result of 8 hard-fought years with a considerable acquired installed base of investment and political prestige. It was a joint effort of all the five university hospitals in Norway, which coincide with five largest hospitals in the country. The decision to replace it was accordingly difficult to reach. In our analysis, we point out how images of an "integrated" alternative acted as an influential rhetorical thrust here. An integrated solution mobilizes strong images and visions of order and perfection, functioning as attractive promises of a brighter future (Swanson and Ramiller 1997). We are concerned with developing a closer understanding of the mechanisms at play and what roles these take in negotiations.

Second, well into the implementation process, the merits of the new solution started to fade. Not altogether surprisingly, the integrated solution---attractive for its seductive simplicity - turned out not to be so straightforward. Unforeseen problems and implications arose, threatening to undermine the entire project. We analyze the manner and form in which these unintended consequences of the integrated solution appear (Berg 1998; Latour 1999), specifically the way disorder was relocated rather than eliminated.

Third, as argued by some scholars, the implications of tighter and better integration, intended to increase order and perfection, may in fact turn out to have exactly the opposite effects (Berg and Timmermans 2000; Hanseth et al. 2004; Law 2003). The very act of integration may indeed produce rather than curb disorder. This suggests a 
highly nonintuitive, deeply disturbing understanding of integration with potentially wide-reaching, yet under-specified, analytical and practical implications well worth exploring. It portrays a lack of integration of any reasonably complex genealogy of information systems as an immanent feature.

\section{CONCEPTUALIZING INTEGRATION IN INFORMATION SYSTEMS}

The integration of healthcare software systems has remained one of the most prominent issues in healthcare software development (Kuhn and Giuse 2001; Mykkänen 2003, p. 173; Xu et al. 2000, p. 157). Boochever (2004:16), for instance, underscores that "system integration would provide the platform for improved workflow, patient throughput and patient safety, as well as decreased cost." Integration is expected to automate the medical processes, such as patient admission, transfer and discharge, ordering of laboratory and radiological examinations or medication, and automatic or on-demand (solicited or unsolicited) receipt of results (Tsiknakis et al. 2002, p. 11). Basically, this includes the four principal classes of hospital-based systems - the EPRs, the laboratory systems, the radiology systems (RIS/PACS), and the patient administrative systems (PAS).

An integrated solution is supposed to give the physicians easy access to data from multiple information sources (Friedman 2001, p. 1529; Tsiknakis et al. 2002, p. 6; Winsten 2000), thus providing a complete picture of the patient's/client's medical history. The multiple information sources are accessed seamlessly from a single point of end-user interaction (Boochever 2004, p. 16). This avoids the physician having to perform redundant activities, such as specifying the patient identifying information over and over again (Ginneken 2002, p. 101). Accordingly, a completely integrated IT solution is a clear goal: "A scalable I-EHR [integrated electronic health record] would provide the means to access all available clinical information, at a corporate, regional, national or even international level" (Tsiknakis et al. 2002, p. 5). The care plan describing what will be performed or what has been performed during the patient's stay clearly benefits clearly from the integration of the patient's laboratory tests, radiology examinations, and treatments (Liu et al. 2001, p. 194).

Despite the high aspiration of an integrated solution, Berg (1998, p. 294) fairly accurately characterizes the situation when he maintains that "fully integrated [EPR] ... is hard to find." One cause is that many software products have been built and acquired from heterogeneous sources during a long period of time, and the systems have differences in implementation technologies and architectures (Mykkänen et al. 2003, p. 173).

Accordingly, it does not come as a surprise that there have been many different strategies and approaches to integration (Hasselbring 2000). These may be seen as an expression of the enormous challenges and difficulties with integration. The integration mechanisms include techrical solutions like federated database systems, World Wide Web (Grimson et al. 1998, p. 124), ERP-systems (Grimson et al. 2000), components (Clayton et al. 2003, p. 2), and Internet portals. Common models and architectures are also suggested (Bernstein et al. 2005). 
Taking one step back from this crude outline, the historical pattern is relatively clear: full integration of information systems in hospitals remains a dream. If this is so, how should we move from here? It seems to us there are two alternative routes. The first amounts to maintaining the ambition and trying out new (technical) mechanisms for integration. As indicated above, this is a well-known strategy with a considerable number of existing suggestions and, surely, quite a few to come. The other alternative, largely unexplored within IS (for an exception, see Hanseth et al. 2004), is more radical. Inspired by recent developments in science studies, it provocatively challenges the root assumption of "full integration," namely the possibility of an all-embracing solution. Such a solution implies strong assumptions of an underlying order and perfection as everything has to fit together. This alternative approach to integration questions the very ambition of integration embedded in full integration: What if the lack of success with integration in hospitals is neither accidental nor transient? What if efforts of producing order always simultaneously produces the opposite? As Berg and Timmermans (2000) point out,

These orders do not emerge out of (and thereby replace) a preexisting disorder. Rather, with the production of an order, a corresponding disorder comes into being....The order and its disorder, we argue, are engaged in a spiraling relationship - they need and embody each other (pp. 36-37).

The two orders [referred to, i.e., two alternative clinical treatments] we have described produce the very disorder they attempt to eradicate (p. 45).

Law (2003) makes a similar point, but pushes further by underscoring the ultimately dysfunctional nature of preserving the ambition of full integration with the implied completeness and perfection.

So what's the argument here? The answer is: it's an argument about imperfection....That there are always many imperfections. And to make perfection in one place (assuming such a thing was possible) would be to risk much greater imperfection in other locations.... The argument is that entropy is chronic..... Some parts of the system will dissolve... For a manager accepting imperfection is not a failing. It is an advantage. Indeed a necessity. Perfectionism would be dangerous (p. 11).

Finally, Latour (1999), in his expositions more recent than the ones that tend to be the most-cited within the IS research community, in a similar manner underlines how ambitions and intentions are never realized.

That action is slightly overtaken by what it acts upon; that it drifts through translation; that an experiment is an event which offers slightly more than its inputs (p. 298).

There is a drift, a slippage, a displacement, which, depending on the case, may be tiny or infinitely large (p. 88). 
Summing up, we discuss and explore analytical and practical implications for integration when information systems are recognized as immanently heterogeneous.

\section{METHOD}

The case study was conducted at the University Hospital of North Norway (UNN). UNN has approximately 4,000 employees, including 400 physicians and 900 nurses. The hospital has 600 beds of which 450 are somatic and 150 psychiatric.

The study belongs to an interpretive research approach (Klein and Myers 1999; Walsham 1993) and includes participant observations, interviews, document analysis, and informal discussions. The data collection was conducted by the first author the results are presented in Table 1.

We endeavored to take the different sources of field data into consideration in the interpretation process. The method included relatively detailed case write-ups for the sites involved (see, for instance, Eisenhardt 1989, p. 540) followed by an examination of our data for potential analytical themes. Whenever something interesting seemed to emerge from the data (Schultze 2000, p. 25), we tried to categorize the data according to these themes in order to make good overviews based on the perspectives chosen.

\section{Table 1. Data Collection Results}

\begin{tabular}{|c|c|}
\hline Participant Observations & $\begin{array}{l}\text { Participation in } 60 \text { project meetings in the Dips } \\
\text { project from its initial stages (January } 2004 \text { ) and } \\
\text { onward. This has also resulted in a } 60 \text { transcribed } \\
\text { documents. } \\
\text { The project members participating in these meetings } \\
\text { were IT consultants, physicians, secretaries, bio- } \\
\text { engineers, and nurses. Their number varied from } 5 \\
\text { to } 16 \text {. }\end{array}$ \\
\hline Informal Talks & $\begin{array}{l}50 \text { notes based on informal talks with participants of } \\
\text { the Dips project and users. }\end{array}$ \\
\hline Interviews & $\begin{array}{l}10 \text { open-ended interviews with a tape recorder of } \\
\text { users of whom } 8 \text { where physicians. }\end{array}$ \\
\hline Document Archive & $\begin{array}{l}400 \text { e-mails sent to the Dips project and the project } \\
\text { document archive consisting of several } 100 \\
\text { documents. }\end{array}$ \\
\hline
\end{tabular}




\section{CASE OUTLINE}

The University Hospital of North Norway (UNN) has for almost 8 years participated in the national and longstanding Medakis project (1996-2003). This project started out as an ambitious, collaborative project between the five Norwegian university hospitals and the vendor Siemens with considerable financial and political backing from the health authorities. The overall goal was to develop a common, all-encompassing EPR for these hospitals, covering the needs of all of the different health professions in different hospital departments (Ellingsen and Monteiro 2003). Despite falling significantly short of these expectations, the DocuLive EPR has been in operational, increasingly wide-spread, use in the five university hospitals for several years.

The key role of EPRs in Norwegian health care is reiterated regularly in health policy programs (SHD 1996, 2001). This, however, has not been sufficient to coordinate an integrated and uniform health care. A sweeping health reform in 2002 shifted the ownership of the Norwegian hospitals from the counties over to the government in an attempt to curb expenditures and poor exploitation of existing resources. The former five health regions were replaced by five regional health enterprises with substantial autonomy, each comprising one of the former university hospitals and several local hospitals.

The Regional Health Enterprise Northern Norway (here referred to as Health Region North), in a surprising decision in December 2003, exercised its newly gained autonomy to break out of the long-term Medakis collaborative effort. As the large university hospital, UNN, was the only hospital in the northern health region running DocuLive EPR, Health Region North decided to replace this system with what the 10 other (smaller) hospitals in the region had, namely, systems from the vendor Dips. The vendor Dips is one of three vendors in the Norwegian hospital-based EPR market. Dips covers about 30 percent of the market through its installations at mostly smaller hospitals (Lærum et al. 2001). The Dips EPR module comes integrated with a radiology module, laboratory module, PAS module, and a psychiatry module.

Health Region North supported the project with 10 million NOK. Beyond that, UNN was assumed to provide the necessary personnel resources. In January 2004, UNN established a Dips implementation group consisting of personnel from UNN and Dips. The initial plans aimed at replacing the EPR and the PAS module by November the same year. The laboratory module was pushed back to a later stage mostly due to lack of resources on the vendor's part. The project decided not to replace the existing RIS module with the RIS module from Dips. The existing RIS module was developed locally at UNN and was considered the better choice.

The pre-project ending in March 2004 identified no major obstacles to the implementation, but concluded that the process amounted to a mere substitution, not requiring user involvement, which should be finished in 3, not 6, months. A key challenge was to ensure that Dips was integrated into the existing, extensive portfolio of information systems, many of which were integrated with the old PAS module.

The project did implement Dips within the three months (by June 2004) and was largely considered a success by the project group. The speedy processes paid the toll with a lack of user training, though, as only half of the physician were put through training sessions. Concerns were also raised when it was discovered that Dips lacked 
some functionality, especially relating to the text editor, signature routines, and administrative routines.

Implementing the Dips laboratory modules was considered crucial for a completely integrated solution. For the Clinical Chemistry, Immunology, and Clinical Pharmacology laboratories, this was an unquestionable argument. Nevertheless, the laboratories were concerned about the new functionality in Dips. The laboratory of Clinical Chemistry had over a period of several years developed its own system which "frankly speaking, we are quite satisfied with," as one expressed it. Since Dips implementation in the summer of 2004, a considerable amount of resources both from Dips and UNN has been poured into developing a laboratory module that could satisfy the different laboratories.

\section{ANALYSIS}

We structure our analysis of integration into three parts focusing on the imagery of "perfect" integration, how simplification in one place is created by reintroducing additional work for others, and how the endeavor to achieve complete integration is selfdefeating.

\subsection{Imagining an Integrated Future}

The perceived messiness of the nonintegrated initial situation made the imagined future with Dips extremely attractive. In line with Law (2003), the rhetorical thrust of a completely orderly and all-encompassing solution was massive as "We want Dips...then we get everything we need." Figure 1 illustrates the situation.

The existing partly nonintegrated IT portfolio

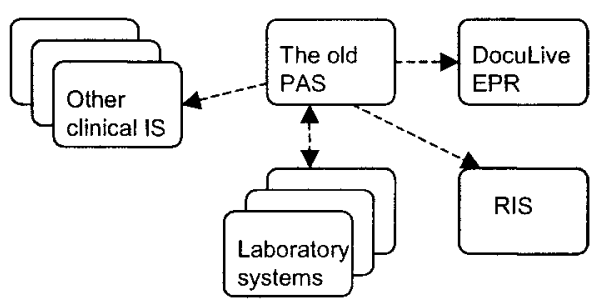

The envisioned integrated Dips portfolio

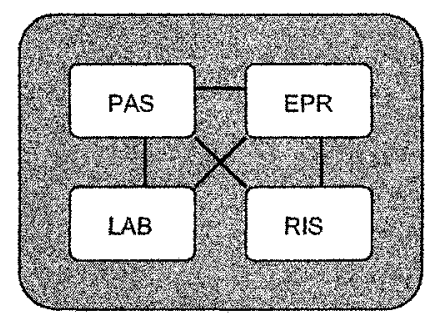

The dotted arrows indicate integration of patient information (date of birth, personal identity number, name, address, etc). The direction of the arrows indicates which way this information flows.

Figure 1. The Existing and the Envisioned IT Portfolio 
Initially, UNN was the only hospital out of 11 in the health region running DocuLive EPR and not Dips. To change this was argued to be common-sense, obvious, thus black-boxing the issue into an invincible argument (Latour 1999). In the words of top IT management in Health Region North, "There are 11 hospitals in this region and 10 running Dips. Therefore it is obvious that UNN should run Dips." The resulting centralization implied that upgrades, user requests, and general database management could be streamlined. Health Region North thus expected significant reduction in expenditures.

Furthermore, the users at UNN (especially the physicians), were dissatisfied with their existing IT portfolio. In daily work, they depended on having access to x-ray descriptions, laboratory results, and the EPR. A lack of mutual integration of their existing PAS, EPR, and laboratory systems made this situation difficult. As one a physician phrased it,

I don't have the laboratory results; I don't have the x-ray description. Instead I have three different logon codes that I have to use on three different systems [DocuLive, Laboratory, and RIS] and I have to leave and enter the different systems in turn.

The users perceived DocuLive EPR as largely a standalone application. In contrast, Dips could presumably offer a complete package including (RIS, PAS, EPR, laboratory system, and psychiatry). The vendor Dips promotes their Dips-modules as a complete and integrated solution.

The Dips solution is based on a common architecture, integrated modules and a common logon-procedure across the different modules.

The Dips modules resided in the same database, implying that some registers in the database are shared between the modules. The modules are developed in the same programming language Delphi, thus offering a coherent user interface. However, taking full advantage of the Dips functionality presupposes that all of these modules are used as a package.

In sum, the replacement of DoucLive EPR with Dips drew on strong visions of a sanitizing or hygienic effort to purge UNN of its perceived mess (Berg and Timmermans 2000; Law 2003).

\subsection{Relocating, Not Eliminating, Disorder}

For sure, the integrated Dips solution improved the access for physicians to clinical information from different sources. It was accordingly perceived as more orderly by most physicians. But as argued by Berg and Timmermans (2000), creating order in one place simultaneously creates disorder in other places. Disorder is relocated and transformed, not eradicated. More specifically, creating order for some creates disorder for others, which spawn work-arounds to amend. The overall level of order and disorder, however, appears to be largely constant. We present three illustrations. 
First, it is the responsibility of the secretaries to update the paper-based patient records. Whenever new information is entered into Dips EPR, print-outs to the paper version are necessary. In DocuLive, the content was sorted by time of document production, making it feasible to print out only the last document. In Dips EPR, however, sorting is by time of consultation. This implied that often a new document was inserted in the middle of many other documents due to various delays. As a result, all of the documents following the new one had to be printed out in order to maintain continuity in the paper record. This was a laborious process that made it more difficult to keep the paper-based record up-to-date.

The printouts in Dips EPR generate more and more chaos. Many documents are already printed out. Then suddenly a new document is produced with consultation date back in time. This document is then inserted [automatically] 15 to 20 documents before the last document (e-mail from a secretary to the project group).

Second, from the outset it was evident that the Dips lab solution and the Dips RIS were not as functional as the existing solution. While the project decided not to replace their locally developed RIS, it was decided to replace the existing laboratory systems. Most of the laboratories agreed, following the largest, the Clinical Chemistry laboratory. A user at this laboratory argued that their reason for participation was that

We take the additional burden to ease the workfor the physicians in the clinic.

After implementing the laboratory module, the laboratories experienced that the routines were more cumbersome than before and they had to hire additional people to manage them. They also had to participate in extensive efforts in further developing the functionality in Dips.

The Microbiology Laboratory was not prepared to undertake the additional work of implementing and using Dips. Here, the users felt that the laboratory module needed significant development in order to make it acceptable.

Dips has altogether nothing that is suitable for us... the problem for everybody that makes laboratory systems is that the vendor starts out where the production is most intensive, and that is clinical chemistry. But clinical chemistry has an incredibly simple data structure (Head physician, Microbiology Laboratory)

This implied among other things that the developers had given little attention to clinical information, material, and location, and finally the grouping, analysis, and assessments of these things. Consequently, the laboratory refused to implement Dips.

Third, even the primary beneficiaries of an integrated solution (the physicians) had to pay a price. They had to accept that the EPR functionality in Dips was poorer than in their old DocuLive EPR. The editor in the EPR was not well-known as was Microsoft Word in DocuLive EPR. The Dips editor lacked simple editor functionality (e.g., a medical dictionary). In addition, the signature routines in Dips EPR turned out to be less flexible. It was not possible to cancel a signature. Despite being able to 
countersign documents, the countersignature did not appear on the letters. Moreover, when a head physician responsible for countersigning made changes to the content, the initial author did not get any notification. The authoring physician could not sign a document whenever other users had opened it. Sometimes this resulted in "man-hunts" for the physician who had opened it and, if unsuccessful, the IT help desk had to free the document in order to enable it to be signed.

\subsection{The Dysfunctional Quest for Perfection}

The introduction of Dips was, as outlined earlier, initially motivated by strong images of order, purification, and efficiency. The IT management at UNN argued that this was "just a simple system replacement of the existing PAS and EPR." However, by viewing it as such a simplification, the very efforts of introducing order are in themselves likely to generate disorder as predicted by Berg and Timmermans (2000), Hanseth et al. (2004), and Law (2003). We provide a few illustrations.

At the core of this was the dramatically underestimated effort of replacing the large installed base of information systems. The Dips project experienced difficulty in obtaining a complete overview of the status of these integrations. As the project leader for the technical team put it,

All those smaller systems imply a chaotic situation. And we don't know who has made the integration, what is integrated and how things are integrated. Moreover we don't know how much [of this functionality] is actually in use.

Therefore, half-way into the implementation it was discovered that completely replacing PAS was extremely risky as many of the existing systems would stop working because they especially depended on functionality provided by the PAS system (searching records, reimbursement functionality, different codes, reports, etc.). As an alternative strategy, the old PAS was kept "alive" alongside with the PAS module in Dips. In this way, all of the other systems could be left untouched (see Figure 2). However, this strategy required integration between the old PAS and Dips PAS in order to maintain the existing information flow and the possibility of uniquely identifying the patients across systems. As a result, the IT department developed a gateway program running on a computer that monitored changes in the Dips PAS. Whenever new patients were inserted into Dips or other changes were made on patient information, this was synchronized with the old PAS.

This caused some additional work for the users of the old IT portfolio. For instance, when a user wanted to create a new sample in one of the laboratory systems, she had to connect the sample to a particular patient. Whenever the patient did not exist in the laboratory system, which regularly was the case, she had to

1. Logon to the Dips system and insert the patient.

2. Wait until the gateway machine had synchronized this information with the old PAS. This process approximately took 3 to 4 minutes

3. The user could then find the patient in the laboratory system (through its integration with the old PAS. 


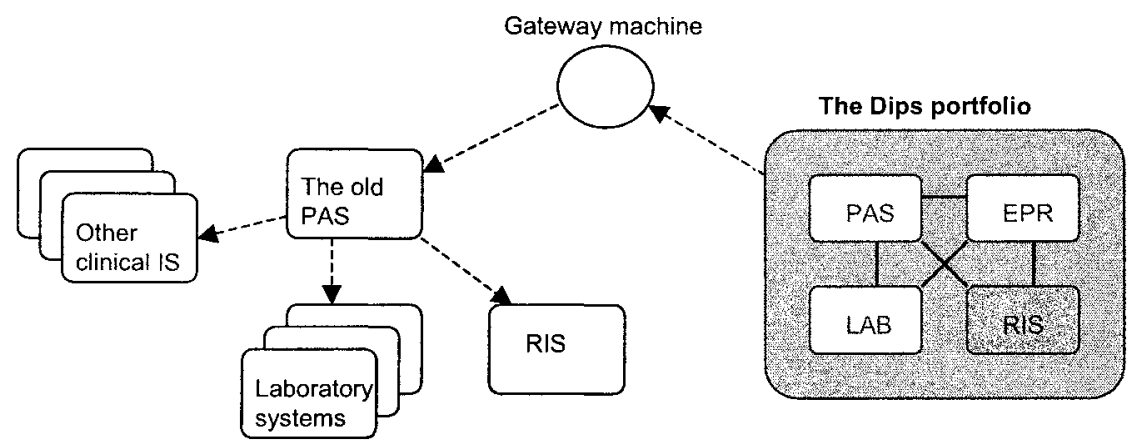

Figure 2. The Gateway Machine

This procedure implied an increased complexity. Users of the old IT portfolio, depending on the gateway machine, also had to use Dips on a daily basis with the only purpose being to insert new patients.

A smooth information flow between the old IT portfolio and Dips was extremely dependent on an up-and-running gateway machine. However, sometimes the gateway machine was down or it failed to synchronize patients (for instance, filled-in data fields were lacking). Therefore, the gateway machine and its associated transactions had to be monitored by IT personnel. In cases of failed synchronisation, the users had to insert new patients in their old IT portfolio anyway. In such cases, the IT personnel had to make the synchronisation manually.

A further complication was how the personal identity number for patients was processed. This number is given to Norwegian citizens some months after their birth, implying that foreigners and newborns don't have this number (or it for other reasons is missing). When these persons had to be registered in the IT portfolio at UNN, an emergency identity number had to be produced. Dips and the old PAS had different rules for producing such a number, implying that the gateway machine had to make a conversion. This implied that the same patient could exist in both the old IT portfolio and in Dips with a different personal identity number, generating uncertainty whether this was the same patient. As a result, yet another program was made, which at the same time accessed both the old PAS and Dips in order to guarantee that the patient was the same.

A fundamental argument for Health Region North was that a standardized Dips solution for every hospital in the region (preferably placed in one location) would make it easier to support Dips. The IT chief in Health Region North underscored this strategy by stating "then every change can be made in one place only." However, after implementing Dips, the IT department at UNN experienced that when parts of the Dips system had to be upgraded, the whole system was influenced. This resulted in the whole system regularly being unavailable for the users. For instance, upgrading the laboratory module implied that the Dips PAS and the Dips EPR module became unavailable for users also. Together with a need for a frequent upgrade policy, this enforced a problem. 
When a new version appears from the vendor once a week, it creates a lot of work for us. It is not just like obtaining the file from Dips and then believing that it is ready for use. We have to make a new installation package each time and this new version must be distributed to 2800 PCs (IT consultant, UNN).

\section{CONCLUSION}

In contrast with more traditional descriptions of integration in IS, we have presented a case where integration efforts, despite good intentions, spawned additional work (work-arounds). Worse still, we have also pointed out examples of self-defeating effects in the sense that integration generates increased levels of disorder. It is, as discussed earlier, always possible to regard these non-intended effects as transient, hinging on particular circumstances in the case narrative. Indeed, some of our illustrations (e.g., the gateway machine) have been partly replaced; some non-intended effects have been amended.

It would, however, seriously underestimate our account to conclude that this puts the project in particular and integration efforts more generally back on track. The gist of our position is that the disorder generated by integration efforts is immanent. When specific instances of this disorder are eliminated, new ones are simultaneously produced, possibly relocated.

This perspective on integration should not be misconstrued as an abstract, purely analytic point. More importantly, it has quite real implications for design, practitioners, and managers. At UNN, the integration efforts were aimed at establishing a more orderly collection of information systems, but more pressing, through this, to support more cost-effective work routines. Initial estimates suggested that expenditures would be reduced with 8.5 million NOK a year (UNN intranet news, published August 10, 2004). As the repercussions of the project unfolded, in strictly economical terms, the integration has been self-defeating, since later estimates suggest that the Dips portfolio will increase the expenditures with 4.5 million NOK a year.

\section{ACKNOWLEDGMENTS}

This research has been partially supported by the Norwegian Centre for Electronic Patient Record Systems (www.nsep.no).

\section{REFERENCES}

Berg, M. "Medical Work and the Computer Based Patient Record: A Sociological Perspective," Methods of Information in Medicine (38), 1998, pp. 294-301.

Berg, M., and Timmermans, S. "Orders and Their Others: On the Constitution of Universalities in Medical Work," Configurations (8), 2000, pp. 31-61.

Bernstein, K, Bruun-Rasmussen, M., Vingtoft, S., Andersen, S. K., and Nøhr, C. "Modeling and Implementing Electronic Health Records in Denmark," International Journal of Medical Informatics, 2004. 
Boochever S. S. "HIS/RIS/PACS Integration: Getting to the Gold Standard," Radiology Management (26:3), May-June 2004, pp. 16-24

Buderi, R. "Computing Goes Everywhere," Technology Review.Com, January/February 2001 (available online at http://www.technologyreview.com/articles/01/01/buderi0101.asp).

Clayton, P. D., Narus, S. P., Huff, S. M., Pryor, T. A., Haug, P. J., Larkin, T., Matney, S., Evans, R. S., Rocha, B. H., Bowes, W. A., III, Holston, F. T., and Gundersen, M. L. "Building a Comprehensive Clinical Information System from Components: The Approach at Intermountain Health Care," Methods of Information in Medicine (42), 2003, pp. 1-7.

Eisenhardt, K. M. "Building Theories from Case Study Research," Academy of Management Review (14:4), 1989, pp. 532-550.

Ellingsen, G., and Monteiro, E. "A Patchwork Planet: Integration and Cooperation in Hospitals," Computer Supported Cooperative Work (12:1), 2003, pp. 71-95.

Friedman, B. A. "The Total Laboratory Solution: A New Laboratory E-Business Model Based on a Vertical Laboratory Meta-Network," Clinical Chemistry (47:8), 2001, pp. 1526-1535.

Ginneken, A. M. "The Computerized Patient Record: Balancing Effort and Benefit," International Journal of Medical Informatics (65), 2002,pp. 97-119.

Grimson, J., Grimson, W., Berry, D., Stephen, G., Felton, E., Kalra, D., Toussaint, P., and Weier, O. W. "A CORBA-Based Integration of Distributed Electronic Healthcare Records Using the Synapses Approach," IEEE Transactions on Information Technology in Biomedicine (2:3), 1998, pp. 124-138.

Grimson, J., Grimson, W., and Hasselbring, W. "The SI Challenge in Health Care," Communications of the ACM (43), 2000, pp. 48-55.

Hanseth, O., Jacucci, E., Grisot, M., and Aanestad, M. "Reflexive Standardization: Side-Effects and Complexity in Standard-Making," unpublished manuscript, 2004.

Hartswood, M., Procter, R., Rouncefield, M., and Slack, R. "Making a Case in Medical Work: Implications for the Electronic Medical Record," Computer Supported Cooperative Work (12:3), 2003, pp. 241-266.

Hasselbring, W. "Information System Integration," Communications of the ACM (43:6), 2000, pp. 32-38.

Klein, H., and Myers, M. "A Set of Principles for Conducting and Evaluating Interpretive Field Studies in Information Systems," MIS Quarterly (23:1), 1999, pp. 67-94.

Kuhn, K. A., and Giuse, D. A. "From Hospital Information Systems to Health Information Systems: Problems, Challenges, Perspectives," Methods of Information in Medicine (4), 2001, pp. 275-287.

Latour, B. Pandora's Hope: Essays on the Reality of Science Studies, Cambridge, MA: Harvard University Press, 1999.

Law, J. "Ladbroke Grove, or How to Think About Failing Systems," Centre for Science Studies, Lancaster University, December 2003 (available online at http://www.comp. lancs.ac.uk/sociology/papers/law-ladbroke-grove-failing-systems.pdf).

Liu, C. T., Long, A. G., Li, Y. C., Tsai, K. C., and Kuo, H. S. "Sharing Patient Care Rrecords Over the World Wide Web," International Journal of Medical Informatics (61), 2001, pp. 189-205.

Lærum, H., Ellingsen, G., and Faxvaag, A. "Doctor's Use of Electronic Medical Records Systems in Hospitals: Cross Sectional Survey," British Medical Journal (323:7325), 2001, pp. 1344-1348.

Mykkänen, J., Porrasmaa, J., Rannanheimo, J,. and Korpela, M. "A Process for Specifying Integration for Multi-Tier Applications in Healthcare," International Journal of Medical Informatics (70), 2003, pp. 173-182. 
SHD. "Governmental Action Programme 2001-2003: Electronic Interaction in the Health and Social Sector "say @," 2001 (available online at http://odin.dep.no/archive/shdvedlegg/ 01/04/Sitek046.doc).

SHD. "More Health for Each BIT: Information Technology as a Means for an Improved Health Service-Action Plan 1997-2000," Ministry of Health and Social Affairs, Norway, 1996.

Schultze, U. "Confessional Account of an Ethnography About Knowledge Work," MIS Quarterly (24:1), 2000, pp. 3-41.

Swanson, E. B., and Ramiller, N. C. "The Organizing Vision in Information Systems Innovation," Organization Science (8:5), 1997, pp. 458-474.

Tsiknakis, M., Katehakis, D. G., and Orphanoudakis, S. C. "An Open, Component-Based Information Infrastructure for Integrated Health Information Networks," International Journal of Medical Informatics (68), 2002, pp. 3-26.

Xu, Y., Sauquet, D., Zapletal, E., Lemaitre, D., and Degoulet, P. "Integration of Medical Applications: The 'Mediator Service' of the SynEx Platform," International Journal of Medical Informatics (58-59), 2000, pp. 157-166.

Walsham, G. Interpreting Information Systems in Organizations, Chichester, UK: John Wiley, 1993.

Winsten D., and McMahan, J. "Integrating Your Radiology Information System in a Complex Computing Environment," Radiology Management (22:4), July-August 2000, pp. 26-28.

\section{ABOUT THE AUTHORS}

Gunnar Ellingsen is affiliated to the newly established study-program on E-health and Telemedicine at the University of Tromsø, Norway. Before completing his $\mathrm{PhD}$ in 2003, he has worked several years as an IT consultant at the University Hospital of North Norway. His research interests centres on the design and use of electronic patient records in hospitals. He has published articles in Information and Organization, Journal of Computer Supported Cooperative Work, Methods of Information in Medicine, Scandinavian Journal of Information Systems, International Journal of IT Standards \& Standardization Research and British Medical Journal. Gunnar can be reached at gunnar.ellingsen@unn.no

Eric Monteiro is professor at the Department of Computer and Information Systems at Norwegian University of Science and Technology. He is broadly interested in organizational transformations and ICT in general, and issues of standardization and globalization in particular. His publication outlets include MIS Quarterly, Journal of CSCW, Science, Technology \& Human Values, Information and Organization, Methods of Information in Medicine, The Information Society, and Scandinavian Journal of Information Systems. Eric can be reached at eric.monteiro@idi.ntnu.no. 


\section{Part 5}

Innovation and Diffusion of Ubiquitous Information Environments 